\begin{tabular}{|c|c|c|}
\hline \multirow{3}{*}{$\begin{array}{r}\text { Case Reports in } \\
\text { Gastroenterology }\end{array}$} & \multirow{2}{*}{\multicolumn{2}{|c|}{ Case Rep Gastroenterol 2015;9:179-187 }} \\
\hline & & \\
\hline & $\begin{array}{l}\text { DOI: } 10.1159 / 000431169 \\
\text { Publisnea onime.:TViay } 29,2015\end{array}$ & $\begin{array}{l}\text { ( } 2015 \text { S. Karger AG, Basel } \\
1662-0631 / 15 / 0092-0179 \$ 39.50 / 0 \\
\text { www.karger.com/crg }\end{array}$ \\
\hline & \multicolumn{2}{|c|}{$\begin{array}{l}\text { This is an Open Access article licensed under the terms of the Creative Common } \\
\text { Attribution-NonCommercial } 3.0 \text { Unported license (CC BY-NC) (www.karger.com/OA } \\
\text { license), applicable to the online version of the article only. Distribution permitted for non } \\
\text { commercial purposes only. }\end{array}$} \\
\hline
\end{tabular}

\title{
Helicobacter suis-Infected Nodular Gastritis and a Review of Diagnostic Sensitivity for Helicobacter heilmannii-Like Organisms
}

\author{
Shigeki Goji ${ }^{a} \quad$ Yasuhiro Tamura $^{\mathrm{a}}$ Makoto Sasaki $^{\mathrm{a}}$ Masahiko Nakamura $^{\mathrm{b}}$ \\ Hidenori Matsui $^{c}$ Somay Yamagata Murayama ${ }^{d}$ Masahide Ebi $^{a}$ \\ Naotaka Ogasawara $^{a}$ Yasushi Funaki $^{\mathrm{a}}$ Kunio Kasugai $^{\mathrm{a}}$ \\ ${ }^{a}$ Department of Gastroenterology, Aichi Medical University School of Medicine, Nagakute, \\ ${ }^{b}$ School of Pharmacy and 'Kitasato Institute for Life Sciences, Kitasato University, Tokyo, \\ and 'Laboratory of Molecular Cell Biology, School of Pharmacy, Nihon University, \\ Funabashi, Japan
}

\section{Key Words}

Helicobacter heilmannii-like organisms · Helicobacter suis - Urea breath test · Rapid urease test . Stool antigen test

\begin{abstract}
Helicobacter heilmannii-like organisms (HHLOs) are associated with mucosa-associated lymphoid tissue lymphoma and peptic ulcer. However, the sensitivity of diagnostic tests for HHLOs, such as rapid urease test (RUT), urea breath test (UBT) and blood antibody, is not high. Tightly coiled spiral microorganisms were found in the gastric mucosal biopsy specimen of a 48-year-old asymptomatic woman. Her findings were positive for RUT and UBT, but negative for blood antibody and stool antigen against $H$. pylori. A 7-day course of esomeprazole, amoxicillin and clarithromycin was administered, resulting in the successful eradication of the HHLOs. Analysis of the 16S rRNA and urease genes suggested a diagnosis of the HHLO H. suis. The sensitivity results of RUT, UBT, culture, blood antibody, immunohistochemistry and stool antigen were 40.0, 14.8, 0, 23.1, 40.0 and $0 \%$, respectively. We report asymptomatic nodular gastritis due to an HHLO. Histological techniques, most likely with smears, are expected to be the most effective method for diagnosing infections by HHLOs, and genetic diagnosis by polymerase chain reaction can be very useful to identify the species of HHLOs.

(c) 2015 S. Karger AG, Basel
\end{abstract}

KARGER 125:s $\quad \begin{aligned} & \text { Makoto Sasaki } \\ & \text { Department of Gastroenterology } \\ & \text { Aichi Medical University School of Medicine } \\ & \text { 1-1 Yazakokarimata, Nagakute, Aichi 480-1195 (Japan) } \\ & \text { E-Mail msasaki@aichi-med-u.ac.jp }\end{aligned}$


Goji et al.: Helicobacter suis-Infected Nodular Gastritis and a Review of Diagnostic Sensitivity for Helicobacter heilmannii-Like Organisms

\section{Introduction}

Helicobacter species are Gram-negative, spiral-shaped bacteria. Helicobacter species other than $H$. pylori, including $H$. heilmannii and $H$. felis, also referred to as $H$. heilmannii-like organisms (HHLOs), have been identified in gastric mucosa-associated lymphoid tissue lymphoma and peptic ulcer in humans. HHLOs are found in a small percentage of human subjects $(0.1-6 \%)[1,2]$; however, HHLO infection is prevalent in gastric mucosa-associated lymphoid tissue lymphoma [3, 4]. HHLO infection is very common in dogs, cats, pigs and nonhuman primates [5, 6].

HHLO infection is most frequently diagnosed by histopathology to identify the organism's morphology. Culture of HHLOs by traditional H. pylori culture techniques is difficult, although one research group has been successful [7]. The ${ }^{13} \mathrm{C}$ urea breath test (UBT) may be used to detect gastric HHLOs in animals [5, 8]. Some human cases have yielded positive results by the rapid urease test (RUT), the UBT and anti-H. pylori antibody, although the sensitivity of these tests is unclear. We report a case of nodular gastritis with HHLO infection diagnosed as $H$. suis by genetic sequencing. We also review the sensitivity of HHLO diagnostic methods.

\section{Methods}

\section{DNA Extraction}

Gastric biopsy samples were digested in SNET buffer (1\% SDS, $400 \mathrm{~mm} \mathrm{NaCl,} 5 \mathrm{~mm}$ EDTA, $20 \mathrm{~mm}$ Tris- $\mathrm{HCl}$, pH 8.0) containing proteinase $\mathrm{K}(0.2 \mathrm{mg} / \mathrm{ml})$ overnight at $50^{\circ} \mathrm{C}$. After 10 -min incubation at $95^{\circ} \mathrm{C}$, the sample was serially diluted tenfold. The DNA was stored at $-20^{\circ} \mathrm{C}$ until use.

\section{Amplification of HHLO-Specific or H. pylori-Specific DNA}

At least 1-, 10- or 100-fold diluted samples were used as DNA templates for polymerase chain reaction (PCR). PCR amplification involved Ampdirect ${ }^{\circledR}$ Plus (Shimadzu Corporation, Kyoto, Japan), BIOTAQ ${ }^{\mathrm{TM}}$ HS DNA Polymerase (Shimadzu Corporation), $0.5 \mu \mathrm{M}$ each of primers HeilF and HeilR (HHLO-specific) or VAC3624F and VAC4041R (H. pylori-specific) [9] using a CFX96 thermal cycler (Bio-Rad Laboratories Inc., Hercules, Calif., USA).

\section{Amplification and Sequencing of Urease Genes}

Urease genes were amplified using primer pairs U430F and U1735R or U430F and U2235R (urease two, 1,752 bp) [10]. The products were sequenced commercially (Fasmac Co. Ltd., Atsugi, Japan) with the same primers and other primers (U850F, U1050R and U1350F] [10]. The sequences were compared with those in the NCBI GenBank by using the BLAST search tool (http://blast.ncbi.nlm.nih.gov/Blast.cgi).

\section{Case Presentation}

In June 2013, a 48-year-old woman was diagnosed with nodular gastritis by esophagogastroduodenal endoscopy at Marin clinic. Histology was positive for HHLO. Nothing abnormal except for gastritis was pointed out. The patient was referred to Aichi Medical University Hospital for treatment in August. She did not have any related medical history and had never come in contact with domestic animals, including cats and dogs. Esophagogastroduodenal 
Goji et al.: Helicobacter suis-Infected Nodular Gastritis and a Review of Diagnostic Sensitivity for Helicobacter heilmannii-Like Organisms

endoscopy showed antral nodular gastritis without mucosal atrophy; the corpus was normal (fig. 1). The ${ }^{13} \mathrm{C}$ UBT finding was positive with a ${ }^{13} \mathrm{C}$ value of $3.3 \%$ (cutoff value $2.5 \%$ ). The RUT (PYLORITEK ${ }^{\circledR}$, Serim Research Corp., Elkhart, Ind., USA) finding was positive in 30 min, but the results of the stool antigen and serum anti-H. pylori IgG antibody tests were negative. However, HHLO of characteristic morphology was found in the antral mucosa and in a gastric pit only (fig. 2). Histopathology showed mild chronic gastritis in the stomach antrum and corpus mucosa and no atrophy or intestinal metaplasia. The patient was treated with a 7-day course of triple therapy consisting of esomeprazole, amoxicillin and clarithromycin. There were no adverse events. Two months after therapy, UBT findings were negative $(0.8 \%)$.

We obtained informed consent from patients and investigated the HHLO by PCR. An HHLO-specific amplicon was obtained from the sample. The sequences of the 16S rRNA gene $(1,167 \mathrm{bp}$; fig. 3a) and the urease gene $(916 \mathrm{bp}$, including a 4-bp undetermined sequence; fig. $3 \mathrm{~b})$ were determined. The 16S rRNA gene sequence of the sample showed $99 \%(1,162$ / $1,167)$ and $96 \%(1,117 / 1,165)$ sequence identity with that of $H$. suis type strain $\mathrm{HS}^{\mathrm{T}}$ (NR_044169) and H. heilmannii type strain ASB1 ${ }^{\mathrm{T}}$ (HE984298), respectively. The urease gene sequence of the sample showed 96\% (882/918) sequence identity with sequences from GenBank accession no. AB968248, AB968247 and AF508001 from H. suis SH8, SH10 and $\mathrm{HU} 4$, respectively. The urease gene had 95\% (772/815) identity with the sequence of $H$. suis type strain $\mathrm{HS1}^{\mathrm{T}}$ (EF204592), whereas it had only 82\% (659/801), 81\% (727/894) and $80 \%(692 / 860)$ identity with corresponding sequences of $H$. bizzozeronii type strain Storkis $^{\mathrm{T}}$ (AF508003), Candidatus H. heilmannii reference strain HU2 ${ }^{\mathrm{R}}$ (AF508012) and $H$. heilmannii type strain ASB1T (HE984298), respectively. On the basis of both sequences, we conclude that the species of the strain is $H$. suis.

\section{Discussion}

We reported an asymptomatic patient with $H$. suis-infected nodular gastritis demonstrated by biopsy specimens. Genetic diagnosis of this infection by PCR was very useful to identify the HHLO species as $H$. suis.

HHLO is a zoonotic agent transmitted from animals to humans [11], and most infected persons complain of dyspepsia, epigastric pain or acid reflux $[12,13]$. However, the current patient had no contact with domestic animals, including cats and dogs. Moreover, she had no symptoms despite histologically mild chronic gastritis. Stolte and colleagues $[3,4,14]$ reported that HHLO infection is more often focal, with fewer organisms, and usually restricted to the gastric antrum, with less severe gastritis than H. pylori infection, leading to the rarity of concurrent erosions and ulcers.

Gastric non-H. pylori helicobacters, which are morphologically long, spiral-shaped bacteria, were originally referred to as Gastrospirillum hominis and later as $H$. heilmannii. $H$. heilmannii was further subdivided in two taxa, types 1 and 2. H. heilmannii type 2 is a group of species that colonize the gastric mucosa: H. felis, H. bizzozeronii, H. salomonis, $H$. cynogastricus, $H$. baculiformis and Candidatus $H$. heilmannii. On the other hand, $H$. suis has been accepted as a new gastric Helicobacter taxon corresponding to type $1 \mathrm{H}$. heilmannii [15]. The cells of this new species are tightly coiled spirals with up to six turns, which are approximately 2.3-6.7 $\mu \mathrm{m}$ long and $0.9-1.2 \mu \mathrm{m}$ wide. They have bipolar tufts of 4-10 sheathed flagella that are blunt-ended or end in spherical knobs [15].

The characteristic morphology of HHLOs can be identified in biopsy specimens stained with hematoxylin and eosin, Giemsa or Warthin-Starry silver stains. The present case was also diagnosed by morphology on the basis of gastric biopsy examination, as in many report- 
Goji et al.: Helicobacter suis-Infected Nodular Gastritis and a Review of Diagnostic Sensitivity for Helicobacter heilmannii-Like Organisms

ed cases. However, HHLOs are better diagnosed on smears (touch cytology) than biopsies $[13,16]$ because they are typically found in the mucus layer above the surface and foveolar epithelial cells and do not show the intimate adherence, pedestal formation or invasion in the intercellular spaces often seen with $H$. pylori.

Other diagnostic tests in the present case showed positive results for UBT and RUT and negative results for stool antigen and serum anti-H. pylori IgG antibody. The sensitivity of diagnostic tests for HHLOs is summarized in table 1 . The findings were as follows: RUT $40.0 \%$, UBT $14.8 \%$, culture $0 \%$, blood antibody $23.1 \%$, immunohistochemistry $40.0 \%$ and stool antigen $0 \%$. As expected, in vitro culture of HHLO failed in 55 patients, although culture was successful in the cat stomach [17]. The urease test seems useful for diagnosing HHLO infection, although it is difficult to distinguish HHLO from H. pylori infection. The rate of urease positivity appears to be lower than that for H. pylori. HHLOs probably have a lower amount of urease than H. pylori, and the test might be positive only when numerous organisms are present in the tested specimen. The UBT and RUT tests are highly sensitive and specific for HHLO in animals, and the discrepancy in these diagnostic tests in humans and animals is unclear [5, 7]. Serological and immunohistochemical tests with $H$. pylori antibody yielded lower positivity rates for HHLO than for $H$. pylori infection itself. The enzyme-linked immunosorbent assay of stool with $H$. pylori polyclonal antigens showed cross-reactivity with HHLO antigens. It is critical to develop HHLO-specific antibodies for serological, immunohistochemical and stool tests.

In the present case, PCR was used to identify the species of HHLO as H. suis. PCR-based studies have been used to identify HHLOs in humans [4] and animals $[3,4,18]$. Chisholm and Owen [9] performed PCR using gastric biopsies, showing an HHLO prevalence rate of 2.3\% in Southeast England. However, this prevalence rate is not as high as that diagnosed by morphology. PCR sensitivity for HHLOs may be lower in clinical practice, and the typical morphological features on hematoxylin and eosin staining seem sufficient to diagnose HHLO infection with chronic gastritis.

\section{Conclusion}

We describe asymptomatic nodular gastritis infection associated with an HHLO. Histological techniques, most likely with smears, will be the most effective method for diagnosing HHLO infection. Furthermore, genetic diagnosis by PCR was shown to be very useful to identify the species of non- $H$. pylori helicobacters.

\section{Acknowledgement}

We would like to thank Editage (www.editage.jp) for English language editing.

\section{Disclosure Statement}

None of the contributing authors have any conflict of interest, including specific financial interests or relationships and affiliations relevant to the subject matter or materials discussed in this paper. 
Goji et al.: Helicobacter suis-Infected Nodular Gastritis and a Review of Diagnostic Sensitivity for Helicobacter heilmannii-Like Organisms

\section{References}

1 Ierardi E, Monno RA, Gentile A, Francavilla R, Burattini O, Marangi S, Pollice L, Francavilla A: Helicobacter heilmannii gastritis: a histological and immunohistochemical trait. J Clin Pathol 2001;54:774-777.

-2 Yakoob J, Abbas Z, Khan R, Naz S, Ahmad Z, Islam M, Awan S, Jafri F, Jafri W: Prevalence of non Helicobacter pylori species in patients presenting with dyspepsia. BMC Gastroenterol 2012;12:3.

-3 Stolte M, Bayerdorffer E, Morgner A, Alpen B, Wundisch T, Thiede C, Neubauer A: Helicobacter and gastric MALT lymphoma. Gut 2002;50(suppl 3):III19-III24.

-4 Morgner A, Lehn N, Andersen LP, Thiede C, Bennedsen M, Trebesius K, Neubauer B, Neubauer A, Stolte M, Bayerdorffer E: Helicobacter heilmannii-associated primary gastric low-grade MALT lymphoma: complete remission after curing the infection. Gastroenterology 2000;118:821-828.

-5 Neiger R, Dieterich C, Burnens A, Waldvogel A, Corthesy-Theulaz I, Halter F, Lauterburg B, Schmassmann A: Detection and prevalence of Helicobacter infection in pet cats. J Clin Microbiol 1998;36:634-637.

-6 Queiroz DM, Rocha GA, Mendes EN, De Moura SB, De Oliveira AM, Miranda D: Association between Helicobacter and gastric ulcer disease of the pars esophagea in swine. Gastroenterology 1996;111:19-27.

-7 Trevena WB, Hooper RS, Wray C, Willshaw GA, Cheasty T, Domingue G: Vero cytotoxin-producing Escherichia coli 0157 associated with companion animals. Vet Rec 1996;138:400.

-8 Kubota S, Ohno K, Tsukamoto A, Maeda S, Murata Y, Nakashima K, Fukushima K, Uchida K, Fujino Y, Tsujimoto H: Value of the 13C-urea breath test for detection of gastric Helicobacter spp. infection in dogs undergoing endoscopic examination. J Vet Med Sci 2013;75:1049-1054.

-9 Chisholm SA, Owen RJ: Development and application of a novel screening PCR assay for direct detection of 'Helicobacter heilmannii'-like organisms in human gastric biopsies in Southeast England. Diagn Microbiol Infect Dis 2003;46:1-7.

10 O’Rourke JL, Solnick JV, Neilan BA, Seidel K, Hayter R, Hansen LM, Lee A: Description of 'Candidatus Helicobacter heilmannii' based on DNA sequence analysis of $16 \mathrm{~S}$ rRNA and urease genes. Int J Syst Evol Microbiol 2004;54:2203-2211.

11 Baele M, Pasmans F, Flahou B, Chiers K, Ducatelle R, Haesebrouck F: Non-Helicobacter pylori helicobacters detected in the stomach of humans comprise several naturally occurring Helicobacter species in animals. FEMS Immunol Med Microbiol 2009;55:306-313.

12 Hilzenrat N, Lamoureux E, Weintrub I, Alpert E, Lichter M, Alpert L: Helicobacter heilmannii-like spiral bacteria in gastric mucosal biopsies. Prevalence and clinical significance. Arch Pathol Lab Med 1995;119: 1149-1153.

13 Debongnie JC, Donnay M, Mairesse J: Gastrospirillum hominis ('Helicobacter heilmannii'): a cause of gastritis, sometimes transient, better diagnosed by touch cytology? Am J Gastroenterol 1995;90:411-416.

14 Stolte M, Kroher G, Meining A, Morgner A, Bayerdorffer E, Bethke B: A comparison of Helicobacter pylori and H. heilmannii gastritis. A matched control study involving 404 patients. Scand J Gastroenterol 1997;32: 28-33.

15 Baele M, Decostere A, Vandamme P, Ceelen L, Hellemans A, Mast J, Chiers K, Ducatelle R, Haesebrouck F: Isolation and characterization of Helicobacter suis sp. nov. from pig stomachs. Int J Syst Evol Microbiol 2008;58:1350-1358.

16 Debongnie JC, Donnay M, Mairesse J, Lamy V, Dekoninck X, Ramdani B: Gastric ulcers and Helicobacter heilmannii. Eur J Gastroenterol Hepatol 1998;10:251-254.

17 Lee A, Dent J, Hazell S, McNulty C: Origin of spiral organisms in human gastric antrum. Lancet 1988;1: 300-301.

$\checkmark 18$ Norris CR, Marks SL, Eaton KA, Torabian SZ, Munn RJ, Solnick JV: Healthy cats are commonly colonized with 'Helicobacter heilmannii' that is associated with minimal gastritis. J Clin Microbiol 1999;37:189-194.

19 Dye KR, Marshall BJ, Frierson HF Jr, Guerrant RL, McCallum RW: Ultrastructure of another spiral organism associated with human gastritis. Dig Dis Sci 1989;34:1787-1791.

$\$ 20$ Morris A, Ali MR, Thomsen L, Hollis B: Tightly spiral shaped bacteria in the human stomach: another cause of active chronic gastritis? Gut 1990;31:139-143. Figura N, Guglielmetti P, Quaranta S: Spiral shaped bacteria in gastric mucosa. J Clin Pathol 1990;43:173. Fischer R, Samisch W, Schwenke E: 'Gastrospirillum hominis': Another four cases. Lancet 1990;335:59. Wegmann W, Aschwanden M, Schaub N, Aenishanslin W, Gyr K: Gastritis associated with Gastrospirillum hominis - a zoonosis? Schweiz Med Wochenschr 1991;121:245-254.

24 Borody TJ, George LL, Brandl S, Andrews P, Ostapowicz N, Hyland L, Devine M: Helicobacter pylori-negative duodenal ulcer. Am J Gastroenterol 1991;86:1154-1157.

25 Mazzucchelli L, Wilder-Smith CH, Ruchti C, Meyer-Wyss B, Merki HS: Gastrospirillum hominis in asymptomatic, healthy individuals. Dig Dis Sci 1993;38:2087-2089.

26 Lavelle JP, Landas S, Mitros FA, Conklin JL: Acute gastritis associated with spiral organisms from cats. Dig Dis Sci 1994;39:744-750.

27 Yang H, Li X, Xu Z, Zhou D: 'Helicobacter heilmannii' infection in a patient with gastric cancer. Dig Dis Sci 1995;40:1013-1014. 
Goji et al.: Helicobacter suis-Infected Nodular Gastritis and a Review of Diagnostic Sensitivity for Helicobacter heilmannii-Like Organisms

28 Akin OY, Tsou VM, Werner AL: Gastrospirillum hominis-associated chronic active gastritis. Pediatr Pathol Lab Med 1995;15:429-435.

29 Koyanagi M, Tanaka M, Nishi T, Kawaguchi H, Kudo H: Acute gastric mucosal lesions accompanied by Gastrospirillum hominis, report of a case. Stomach Intestine 1995;30:1079-1083.

-30 Goddard AF, Logan RP, Atherton JC, Jenkins D, Spiller RC: Healing of duodenal ulcer after eradication of Helicobacter heilmannii. Lancet 1997;349:1815-1816.

31 Isomoto H, Matsunaga K, Shikuwa S, Ofukuji M, Mizuta Y, Makiyama K, Kohno S: A case of Gastrospirillum hominis-associated corpus gastritis. Gastroenterol Endosc 1997;39:68-72.

-32 Chen Y, Zhou D, Wang J: Biological diagnostic and therapeutic study on the infection of Helicobacter heilmannii. Zhonghua Yi Xue Za Zhi 1998;78:490-493.

33 Jhala D, Jhala N, Lechago J, Haber M: Helicobacter heilmannii gastritis: association with acid peptic diseases and comparison with Helicobacter pylori gastritis. Mod Pathol 1999;12:534-538.

-34 Yamamoto T, Matsumoto J, Shiota K, Kitajima S, Goto M, Imaizumi M, Arima T: Helicobacter heilmannii associated erosive gastritis. Intern Med 1999;38:240-243.

-35 Kamoshida T, Hotta S, Hirai S, Oka Y: A case of Helicobacter heilmannii-associated antral gastritis diagnosed by McMullen modified staining. Gastroenterol Endosc 2000;42:974-979.

-36 Yoshimura M, Isomoto H, Shikuwa S, Osabe M, Matsunaga K, Omagari K, Mizuta Y, Murase K, Murata I, Kohno S: A case of acute gastric mucosal lesions associated with Helicobacter heilmannii infection. Helicobacter 2002;7:322-326.

-37 Boyanova L, Koumanova R, Lazarova E, Jelev C: Helicobacter pylori and Helicobacter heilmannii in children. A Bulgarian study. Diagn Microbiol Infect Dis 2003;46:249-252.

-38 Singhal AV, Sepulveda AR: Helicobacter heilmannii gastritis: a case study with review of literature. Am J Surg Pathol 2005;29:1537-1539.

-39 Kato S, Ozawa K, Sekine H, Ohyauchi M, Shimosegawa T, Minoura T, Iinuma K: Helicobacter heilmannii infection in a child after successful eradication of Helicobacter pylori: case report and review of literature. J Gastroenterol 2005;40:94-97.

40 Oyauchi M, Ohara S, Sekine H, Shimosegawa T: Barrett's adenocarcinoma with Helicobacter heilmannii infection, report of a case. Stomach Intestine 2006;41:1089-1093.

-41 Boyanova L, Lazarova E, Jelev C, Gergova G, Mitov I: Helicobacter pylori and Helicobacter heilmannii in untreated Bulgarian children over a period of 10 years. J Med Microbiol 2007;56:1081-1085.

42 Qualia CM, Katzman PJ, Brown MR, Kooros K: A report of two children with Helicobacter heilmannii gastritis and review of the literature. Pediatr Dev Pathol 2007;10:391-394.

$\checkmark 43$ Ohtaka M, Tatsumi A, Fukasawa M, Yamaguchi T, Uetake T, Ohtska H, Sato T, Enomoto N, Watanabe H, Mitani K: Complete remission of gastric plasmacytoma following eradication of 'Candidatus Helicobacter heilmannii'. Clin J Gastroenterol 2012;5:158-163.

44 Matsumoto T, Kawakubo M, Akamatsu T, Koide N, Ogiwara N, Kubota S, Sugano M, Kawakami Y, Katsuyama T, Ota H: Helicobacter heilmannii sensu stricto-related gastric ulcers: a case report. World J Gastroenterol 2014;20:3376-3382. 


\begin{tabular}{ll|l} 
Case Reports in & \multicolumn{2}{l}{ Case Rep Gastroenterol 2015;9:179-187 } \\
\cline { 2 - 3 } Gastroenterology & DOI: 10.1159/000431169 & $\begin{array}{l}\text { ○ 2015 S. Karger AG, Basel } \\
\text { www.karger.com/crg }\end{array}$ \\
\cline { 2 - 3 } & Goji et al.: Helicobacter suis-Infected Nodular Gastritis and a Review of Diagnostic
\end{tabular}
Sensitivity for Helicobacter heilmannii-Like Organisms

Table 1. Sensitivity of diagnostic tests for HHLOs

\begin{tabular}{|c|c|c|c|c|c|c|c|c|c|c|c|c|c|c|}
\hline \multirow[t]{2}{*}{ Year } & \multirow[t]{2}{*}{ First author } & \multicolumn{2}{|c|}{ RUT } & \multicolumn{2}{|c|}{ UBT } & \multicolumn{2}{|c|}{ Culture } & \multicolumn{2}{|c|}{$\begin{array}{l}\text { Blood Ab } \\
\text { (H. pylori) }\end{array}$} & \multicolumn{2}{|c|}{$\begin{array}{l}\text { IHC } \\
\text { (H. pylori) }\end{array}$} & \multicolumn{2}{|c|}{$\begin{array}{l}\text { Stool Ag } \\
\text { (H.pylori) }\end{array}$} & \multirow[t]{2}{*}{$\begin{array}{l}\text { Refer- } \\
\text { ence }\end{array}$} \\
\hline & & + & - & + & - & + & - & + & - & + & - & + & - & \\
\hline 1989 & Dye & 2 & 0 & & & 0 & 1 & & & & & & & 19 \\
\hline 1990 & Morris & 2 & 0 & & & 0 & 2 & 0 & 2 & & & & & 20 \\
\hline 1990 & Figura & 1 & 1 & & & 0 & 2 & 0 & 2 & & & & & 21 \\
\hline 1990 & Fischer & 0 & 4 & & & 0 & 3 & & & & & & & 22 \\
\hline 1991 & Wegmann & 2 & 3 & & & & & & & & & & & 23 \\
\hline 1991 & Borody & 0 & 2 & & & 0 & 2 & & & & & & & 24 \\
\hline 1993 & Mazzucchelli & 0 & 2 & 0 & 2 & 0 & 2 & & & & & & & 25 \\
\hline 1994 & Lavelle & 1 & 0 & & & & & & & & & & & 26 \\
\hline 1995 & Yang & 1 & 0 & & & & & & & & & & & 27 \\
\hline 1995 & Hilzenrat & & & & & & & 0 & 3 & & & & & 12 \\
\hline 1995 & Akin & 1 & 0 & & & & & & & & & & & 28 \\
\hline 1995 & Koyanagi & & & & & & & & & 0 & 1 & & & 29 \\
\hline 1997 & Goddard & 1 & 0 & & & 0 & 1 & & & & & & & 30 \\
\hline 1997 & Isomoto & & & & & & & 0 & 1 & & & & & 31 \\
\hline 1998 & Chen & 14 & 6 & 3 & 17 & 0 & 20 & & & & & & & 32 \\
\hline 1998 & Debongnie & 1 & 8 & & & 0 & 7 & 1 & 8 & & & & & 16 \\
\hline 1999 & Jhala & 3 & 2 & & & 0 & 4 & 5 & 0 & & & & & 33 \\
\hline 1999 & Yamamoto & 1 & 0 & & & 0 & 1 & 0 & 1 & 0 & 1 & & & 34 \\
\hline 2000 & Kamoshida & 1 & 0 & & & 0 & 1 & & & 0 & 1 & & & 35 \\
\hline 2002 & Yoshimura & 1 & 0 & & & 0 & 1 & & & & & & & 36 \\
\hline 2003 & Boyanova & 1 & 0 & & & 0 & 1 & & & & & & & 37 \\
\hline 2005 & Singhal & & & & & & & & & 1 & 0 & & & 38 \\
\hline 2005 & Kato & & & 0 & 1 & 0 & 1 & & & & & 0 & 1 & 39 \\
\hline 2006 & Oyauchi & 1 & 0 & 0 & 1 & 0 & 1 & 0 & 1 & & & 0 & 1 & 40 \\
\hline 2007 & Boyanova & 2 & 0 & & & 0 & 2 & & & & & & & 41 \\
\hline 2007 & Qualia & 1 & 1 & & & & & & & & & & & 42 \\
\hline 2012 & Ohtaka & & & 0 & 1 & & & 0 & 1 & & & & & 43 \\
\hline 2014 & Matsumoto & & & 0 & 1 & 0 & 1 & & & 1 & 0 & & & 44 \\
\hline 2015 & Goji & 1 & 0 & 1 & 0 & & & 0 & 1 & & & 0 & 1 & $\begin{array}{l}\text { present } \\
\text { case }\end{array}$ \\
\hline \multirow{2}{*}{\multicolumn{2}{|c|}{$\begin{array}{l}\text { Total } \\
\text { Positive rate }\end{array}$}} & \multirow{2}{*}{\multicolumn{2}{|c|}{$40.0 \%$}} & 4 & 23 & 0 & 55 & 6 & 20 & 2 & 3 & 0 & 3 & \\
\hline & & & & \multicolumn{2}{|c|}{$14.8 \%$} & \multicolumn{2}{|c|}{$0 \%$} & \multicolumn{2}{|c|}{$23.1 \%$} & \multicolumn{2}{|c|}{$40.0 \%$} & \multicolumn{2}{|c|}{$0 \%$} & \\
\hline
\end{tabular}

$\mathrm{Ab}=$ Antibody; $\mathrm{Ag}=$ antigen; $\mathrm{IHC}=$ immunohistochemistry. 
Case Reports in
Gastroenterology
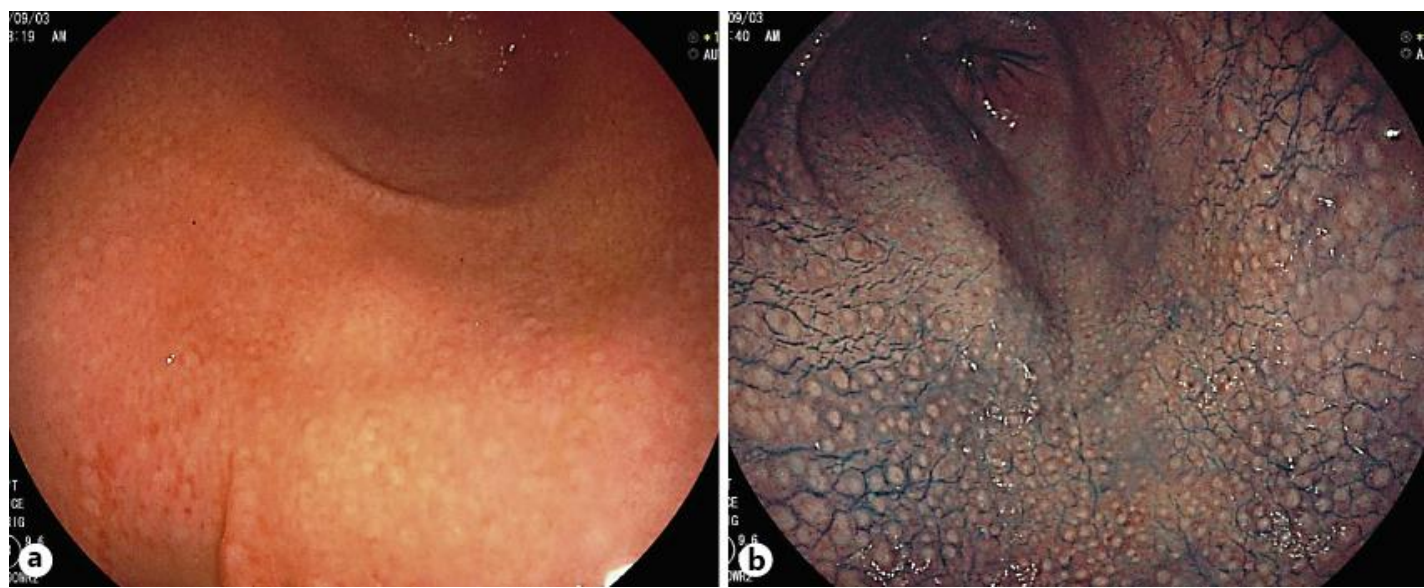

Fig. 1. a White light endoscopy of the antrum showed small, round, yellowish-white nodules, which were the features of $H$. pylori-infected mucosa. $\mathbf{b}$ The nodular pattern can be clearly observed with indigo carmine spreading.

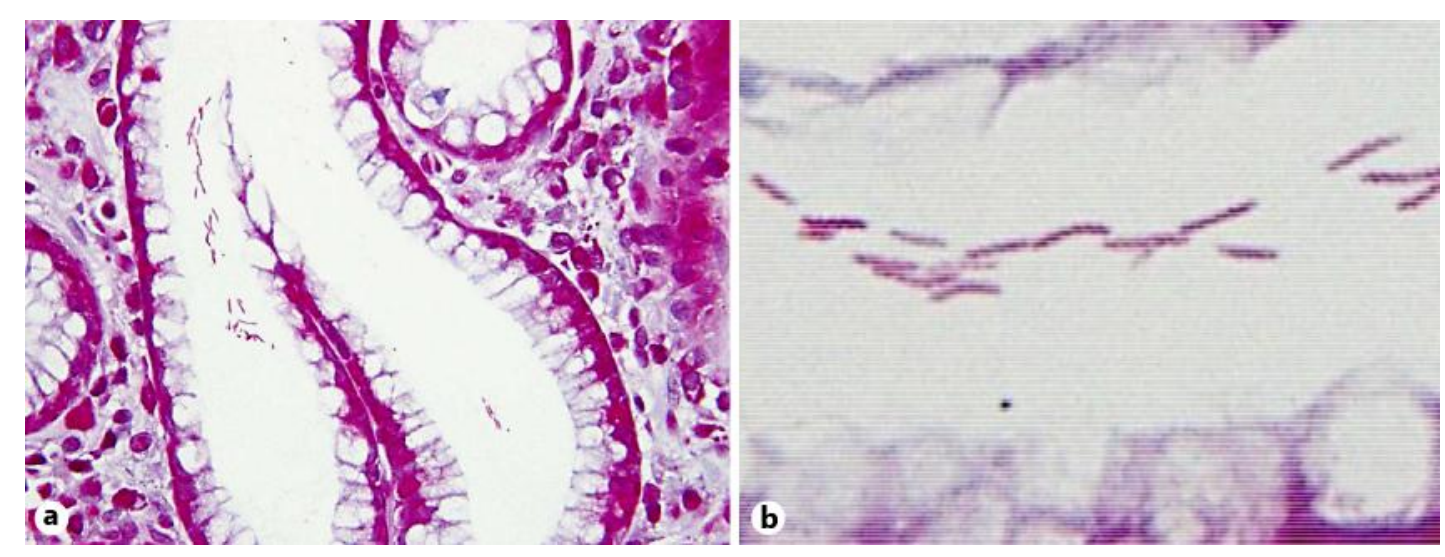

Fig. 2. a Gimenez staining of the antral mucosa showed mild chronic gastritis and microbial colonies in a pit $(\times 400)$. b Long, tightly spiraled microorganisms were observed $(\times 1,000)$. 
Goji et al.: Helicobacter suis-Infected Nodular Gastritis and a Review of Diagnostic Sensitivity for Helicobacter heilmannii-Like Organisms

\section{S rRNA gene sequence (1167 bp)}

GGGCAGTAGCTGCTTTAGCATCCTGACTTAAGGCAAACACAACTCCCATGGTGTGACGGGCGGTGAGTACAAGA CCCGGGAACGTATTCACCGCAACATAGCTGATTTGCGATTACTAGCGATTCCAGCTTCATGCAGGCGAGTTGCAGC CTGCAATCCGAACTAGGAGGTGTTTTATAGATTAGCTCTGCCTCGCGGCTTTGCATCTCTTTGTGCACCCCATTGTA GCACGTGTGTAGCCCTAGGCGTAAGGGCCATGATGACTTGACGTCGTCCTCACCTTCCTCCTGCTTACGCAGGCAG TCTTCTTAGAGTGCGCAGCATAACCTGTTAGCAACTAAGAAAAAGGGTTGCGCTCGTTGCGGGACTTAACCCAAC ATCTCACGACACGAGCTGACGACAGCCGTGCAGCACCTGTTTTCAGGGTCTAGCAAGCTAGACACTCCCCTATTTC TAGGGAATTCCTTCAATGTCAAGCCTAGGTAAGGTTCTTCGTGTAACATCGAATTAAACCACATGCTCCACCGCTTG TGCGGGTCCCCGTCTATTCCTTTGAGTTTTAATCTTGGGACCGTACTCCCCAGGCGGGATGCTTAAGGCGTTAGCT GCATTACTGGAAAGACAAAGCTTTCCAACAACTAGCATCCATCGTTTAGGGCGTGGACTACCAGGGTATCTAATCC TGTTTGCTCCCCACGCTTTCGTGCAATCAGCGTCAGTGATGTTCCAGCAGGTCGCCTTCGCAATGAGTATTCCTCTT GATCTCTACGGATTTTACCCCTACACCAAGAATTCCACCTACCTCTCCCACACTCCAGAAGGATAGTTTCAAATGCA GTTCTATGGTTAAGCCATAGGATTTCACACCTGACTTGTCCTCCCGCCTACGCACTCTTTACGCCCAGTGATTCCGA GTAACGCTTGCACCCTCCGTATTACCGCGGCTGCTGGCACGGAGTTAGCCGGTGCTTATTCGTTAGATACCGTCATT ATCTTCTCTAACAAAAGGAGTTTACGATCCTAAAACCTTCATCCTCCACGCGGCGTTGCTGCTTCAGGGTTTCCCCC ATTGAGCAATATTCCCTACTGCTGCCTCCCGTAGGAGTCTGGACCGTGTCTCAGTTCCAGTGTGTCCGCTCACCCTC TCAGGCCGGATACCCGTCATAG

a

\section{Urease gene sequence (916 bp)}

TCGGTGTGGATAGCCACTTGTACATCATACTCATCAGCAATTTTAAGAGCATGGTGGATAGCTGAAGGTGTGCTGC CCCAGTCTTCATGGATTTTAAAGCCAATAGCCCCAGCTTCCAAGTTGGTCAACCAAAGAAGGTTCATAAGAAACCT TACCTTTACCCATGTAGCCTAAATTCATGGCGTATTCTTCAGAGGCGCGGAGCATTTCTTTTTAAATTCCAGCGGCCT GGAGTGATAGTTGTCGCATTAGTACCATCAGCAGGGCCTGTTCCGCCTCCAAGCATGGTTGTAATGCCGCTAGCAA AAGCGGTGGGGATTTGTTGTGGAGAAATAAAGTGAATGTGGGTATCAATCCCGCCAGCTGTAACAATTAAACCTT CACCAGCTAGTGCTTCTGTAGCAGGACCTACACAAAGGCGGTTGCAAACGCCGTCTTGAATGTCTTTATTGCCGGC TTTACCAATGCCATGGATCTTGCCATCTTTAATGCNAATGTCGGCTTTGTAANTCCCGGTGTAGTTTACAATTAGGG CGTTAGTAATCACTAAATCTAACTCATGGCTGCTGGGGCTATTGGTTTGGCCCATCCCATCGCGGATAGTTTTCCCG CCCCCAAATTTGATTTCTTCGCCATAAGTGGTGCAGTCATGCTCTACTTCTAAAATCAGATATGTATCGCCTAGTCGG AATTTATCGCCTGTAGNGGGGCCATACATAGAAACATATTCTTTCCTAGAGAACACCTCATCGCTTGTCCTTTCCTTA ATTAAATTCGTGATCGCAACCGCAATTAACAGTGCCTAAATGTTTTGGTTTTGGGCGTTTGAGAGCTAAATTTTAGC CACCGTGATCGGCGGGGNCATCTACCAAAGCATTAAAGCCAGAGATGCGTCGANTCCGCGTACATCAATCAAA

b

Fig. 3. The $16 \mathrm{~S}$ rRNA gene $(1,167 \mathrm{bp}, \mathbf{a})$ and the urease gene ( $916 \mathrm{bp}$, b) were sequenced commercially (Fasmac Co. Ltd.). $\mathrm{N}$ = Undetermined gene. 